\title{
مناهج التربية الأخلاقية في معهد تحفيظ القرآن للثانوية
}

\author{
Jurais Mahali, ${ }^{1}$ Akhmad Alim, ${ }^{2}$ Abdul Hayyie ${ }^{3}$ \\ ${ }^{1,2}$ Universitas Ibn Khaldun, Indonesia \\ email: juraismahali92@gmail.com
}

\begin{abstract}
Islam is a very respectful religion good morals. But in reality there are still many from muslim communities do not uphold morals the morals taught by the prophet shalallahu 'Alaihi wasalam, there are many moral violations among the younger generation, such as being arrogant, indifferent, promiscuity, atc. This is what encourages the writer to explor the inner moral education curriculum in the book riyadhu As-Sholihin for senior secondary high school education institutions for the upper secondary level of the tahfidz Al-Qur'an. This research is a literature study with a content analysis approach. This research produces a moral education curriculum, some of wich will be described in this article, namely sincere in words and deeds, repent, patient, piety, amar ma'ruf nahi munkar, and tawadu.
\end{abstract}

Keywords: curriculum, education,morals.

\section{ABSTRAK}

Islam adalah agama yang sangat menjunjung tinggi akhlak Al-Karimah. Namun kenyataannya masih banyak masyarakat muslim yang tidak menjunjung tinggi akhlak yang diajarkan oleh Rasulullah shalallau 'alaihiwasalam, banyak terjadi pelanggaran moral pada generasi muda seperti sombong, acuh taacuh, pergaulan bebas dan lainnya. Hal inilah yang mendorong penulis untuk menggali kurikulum pendidikan akhlak dalam kitab riyadu As-Sholihin untuk lembaga pendidikan tahfidz Al-Qur'an jenjang menengah atas. Penelitian ini merupakan setudi literatur dengan pendekatan Conten alalysis. Penelitian ini menghasilkan kurikulum pendidikan akhlak yang sebagian akan dipaparkan pada artikel ini yaitu ikhlas pada setiap ucapan dan perbuatan, taubah, sabar, takwa, amarma'ruf nahi munkar, tawadu'.

Kata kunci: kurikulum, pendidikan, akhlak. 
الحمد لله رب العالمين رب كل شيء ومليكه، الذي كتب مقادير خلقه قبل خلق السماوات والأراض

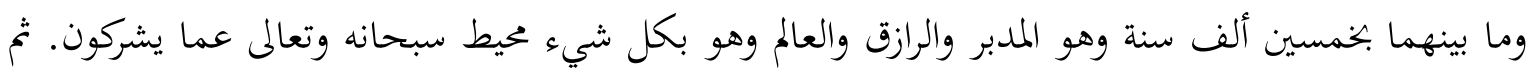

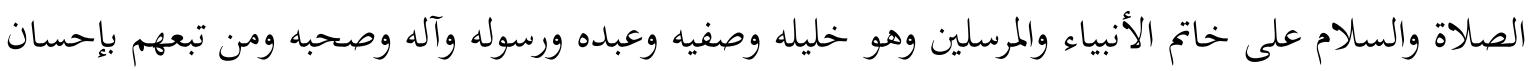

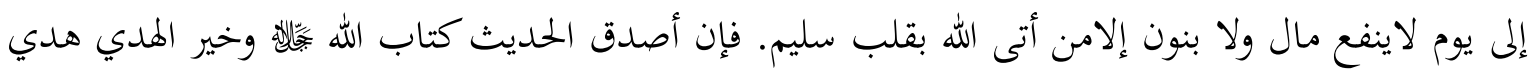

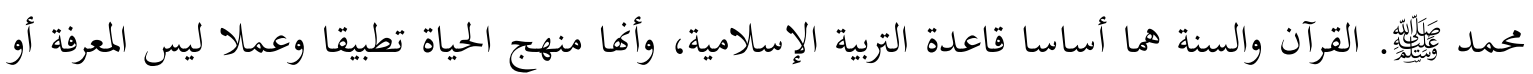

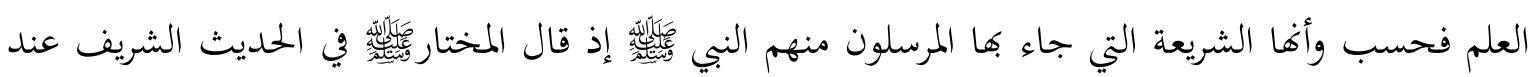

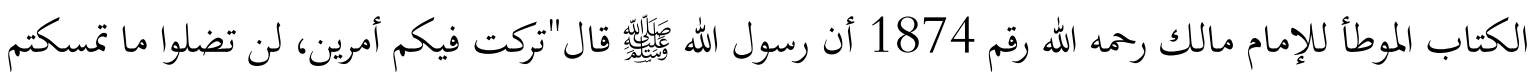
بمما: كتاب الله, وسنّة نبيّه صلى الله عليه وسلم"(مالك:2004) هما أساس الحضارة الإسلامية.

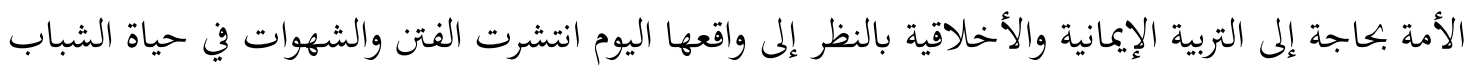

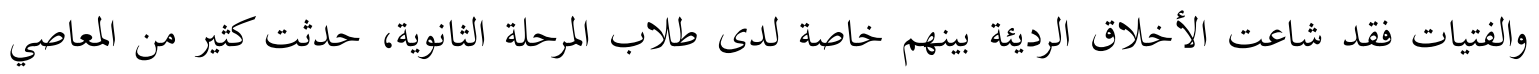

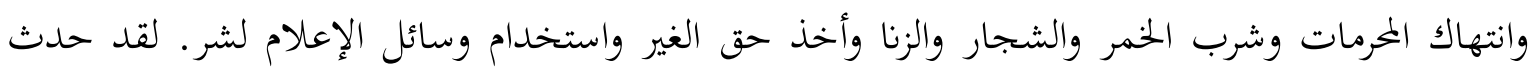

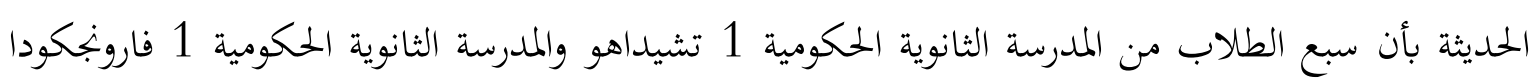

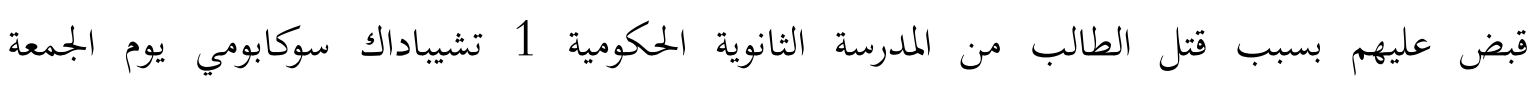

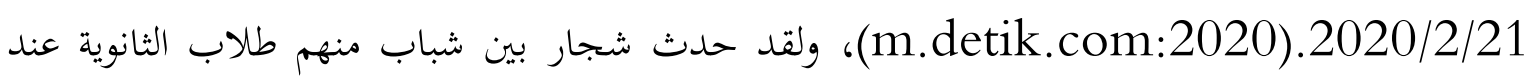

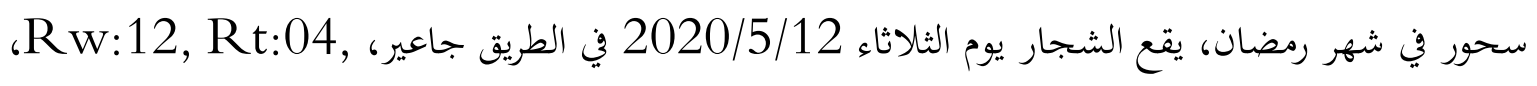

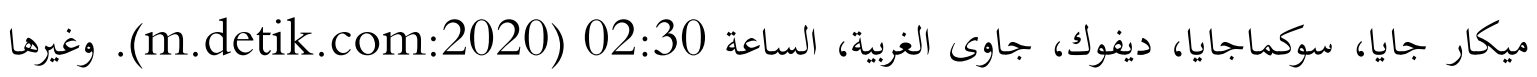

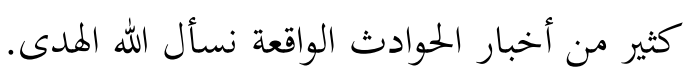

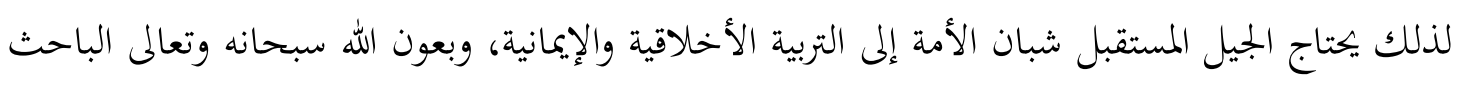

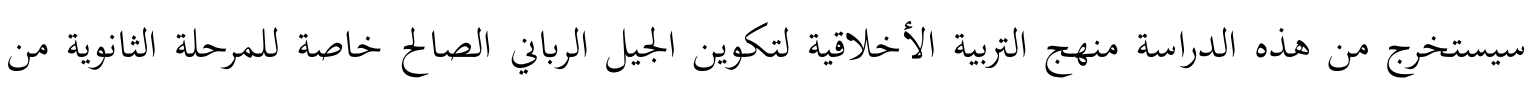

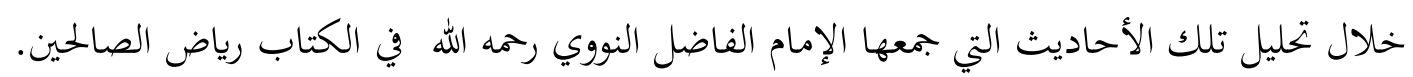

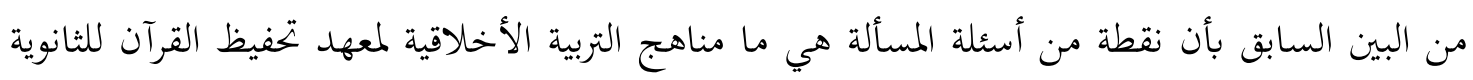

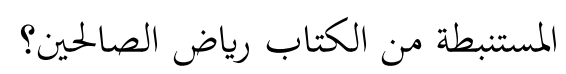

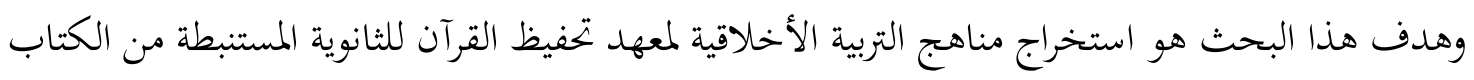
رياض الصالحين الدراسات السابقة بمثل هذا البحث الحثين

الأول. أحمد مسروري (1440هـ) "طريقة أو أسلوب التربية الأخلاقية عند الغزالي في كتابه أيها الولد" بحث علمي

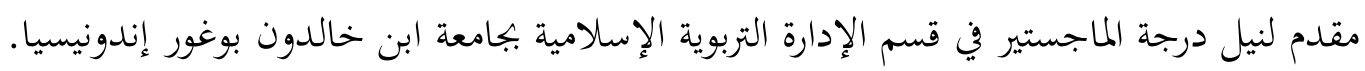


الثاني. أنفال الله (1440هـ) " المنهج التربوي الإسلامي في المدرسة الثانوية دراسة تحليلية لكتاب العلم من الصحيح البخاري وتطبيقها في المدرسة الثانوية المعتوق" بحث علمي مقدم لنيل درجة الماجستير في قسم الإدارة التربوية الإسلامية بجامعة ابن خالدون بوغور إندونيسيا.

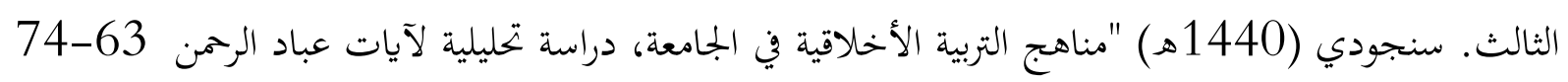
في سورة الفرقان وتطبيقها في جامعة الراية، بحث علمي مقدم لنيل درجة الماجستير في قسم الإدارة التربوية الإسلامية بجامعة ابن خالدون بوغور إندونيسيا. الرابع. محمد عطية إسماعيل اصليح (1430هـ) "مضامين تربوية مستنبطة من كتاب مختصر الترغيب والترهيب للإمام ابن حجر العسقلاني" الرسالة مقدمه لنيل درجة الماجستير في قسم أصول التربية بجامعة الإسلامية -غزة. الخامس. عبد الله بن محمد الإسماعيل (1435هـ) "المضامين التربوية في كتاب بستان العارفين للإمام النووي وتطبيقاتا في مجال الأسرة والمدرسة". بحث مشروع لاستكمال متطلبات الحصول على درجة العالمية (الماجستير) في قسم التربية كلية الدعوة وأصول الدين بجامعة الإسلامية -المدينة المنورة

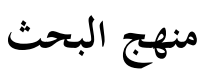

اتخذ الباحث منهج هذا البحث هو المنهج الوصفي التحليلي، يكون البحث في الكتاب رياض الصالحين مستعينا بكتاب شرح رياض الصالحين للشيخ العثيمين، وشروحات أخرى.

\section{النتائج مفهوم المنهج}

ذكر في المعجم الوسيط الكلمة المنهج أو المنهاج وجمعها هي مناهج، معناها الطريق الواضح، وفي التنزيل

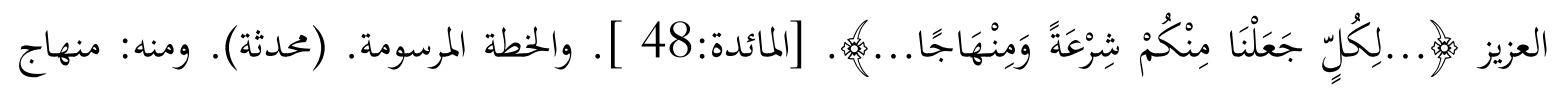
الدراسة، ومنهاج التعليم ونحوها.( 2011 ). ومفهوم المنهج مذكور في دستور الدولة، رقم.20 سنة 2003 عن برنامج تربوية إندونيسية هي بجموعة الخطة، وتنظيم الهدف، والمحتويات، ومادة التدريس، وكذلك طرق التدريس للوصول إلى أهداف التعليم الدولي. (Sarinah, 2012) وقول المتخصص في التربية عمرحماليك في إحدى مؤلفاته بأن المنهج هي برامج التي تحتوي على العناصر المهيمة يرتبط بعضها ببعض مثل محتويات التربية، وأهدافها، وطرقها، وتقويمها. (Oemar Hamalik, 2010) من خلال مفهوم المنهج نستنبط بأنه السبيل لوصول إلى غاية التربية وجميع مايتعلق به من خطة، ومادة، وطريقة، ونشاط، ومحتوية، وغيرها.

\section{مفهوم التربية}

معنى التربية في اللغة أها ترجع إلى الأصول الثلاثة هي: الأول: الكلمة من فعل تربّ، يتربى، تربية بمعنى نشأ وترعرع وتعلّم وتثقِف، "ترى الولد في بيئة طيبة". "اهتم الإسلام بتربية الأطفال"، هذا مذكور في المعجم العربي بين

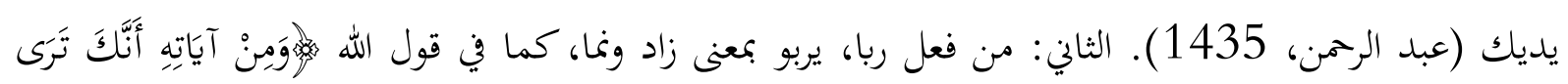

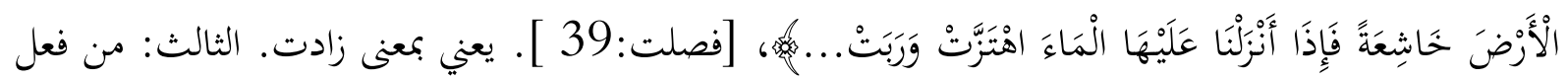

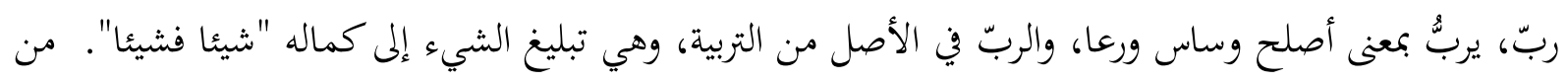


تلك المعاني نستلخص بأن معنى التربية تنحصر في معاني: النمو والإصلاح والنشأة. وهي معنى يكمل بعضها ببعض بما ينتج المفهوم الشامل للتربية. (عبد الله، 2011). ومعنى التربية في الاصطلاح، تبليغ الشيء وتعهده إلى كماله شيئا فشيئا. ( بدرية صالح، 2002).

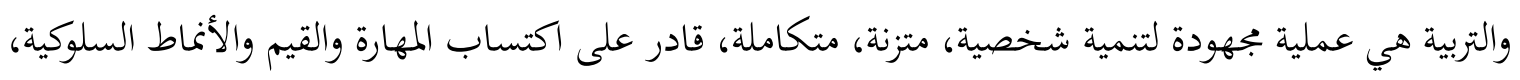

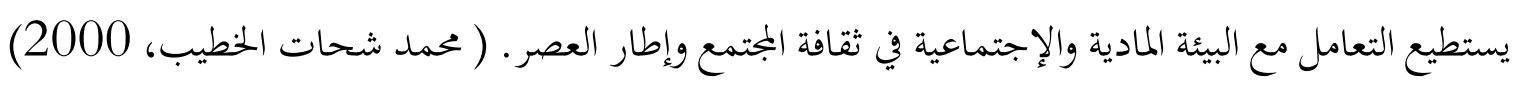

\section{مفهوم الأخلاق}

مفهوم الأخلاق بين بعض العلماء السلف منهم ، الإمام الجرجاني يقول الخلق هو عبارة عن هيئة النفس

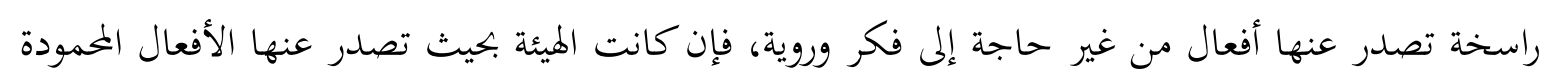

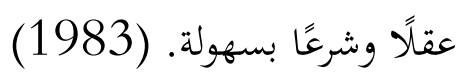

ويقول الشيخ الإسلام ابن تيمية رمه الله بأن الأخلاق مرتبط بمفهوم الإيمان، وما ينبثق عنه حيث إنه تكون

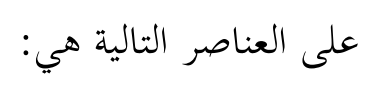
أ. الإيمان بالله يُّاله وحده أنه الخالق، والرازق بيده الملك يعني توحيد الربوبية. ب. معرفة الله هالأ، على أنه وحده المستحق للعبادة يعني توحيد الألوهية.

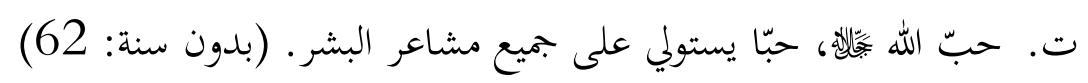

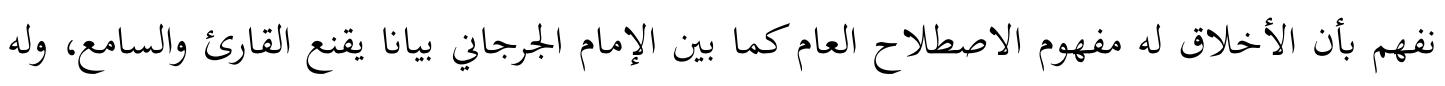

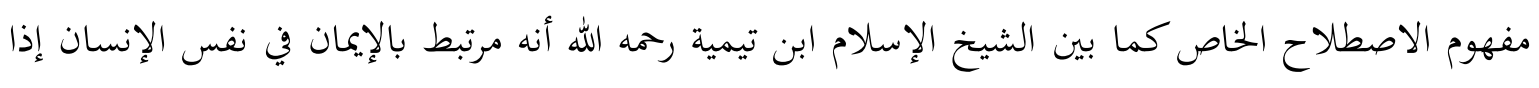

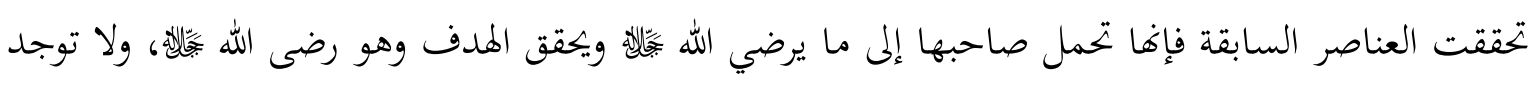

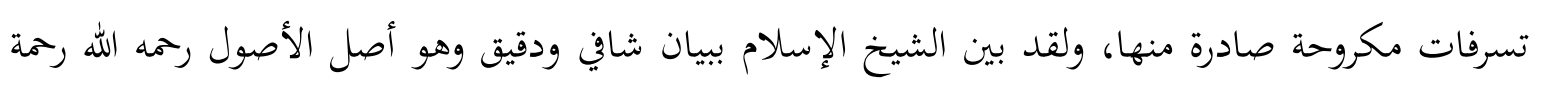

واسعة.

\section{مناهج التربية الأخلاقية في المعهد تحفيظ القرآن للثانوية}

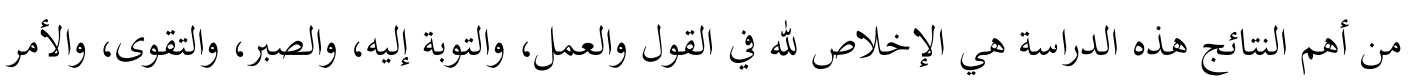

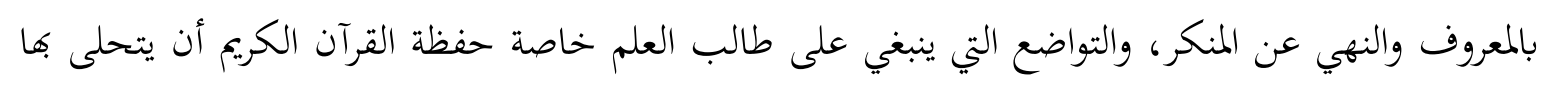
في حياقم. 1. الإخلاص النية في القول والعمل.

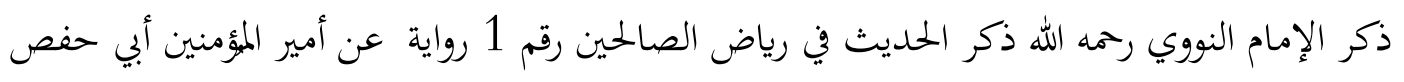

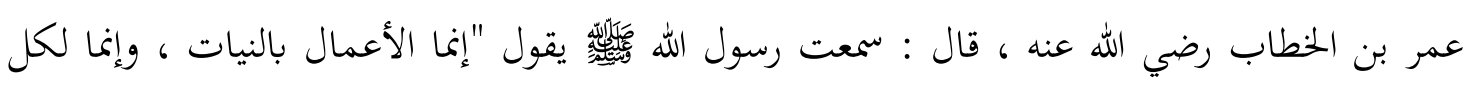

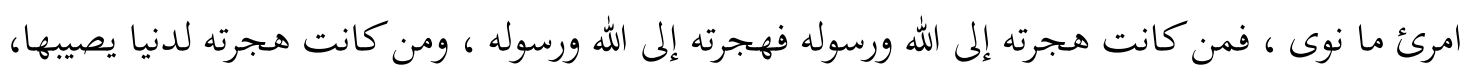

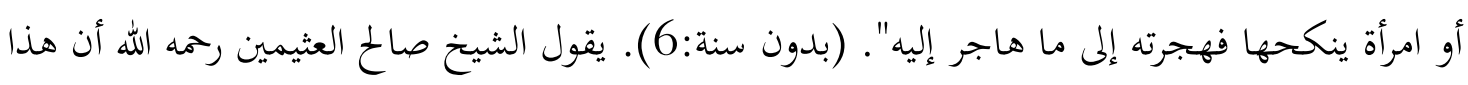

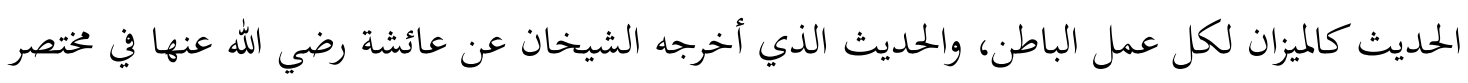

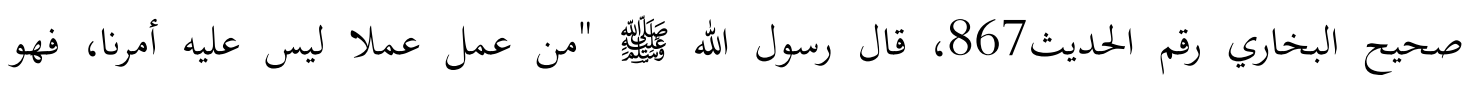


رد"(2002)، الميزان للأعمال الظاهرة، ولذلك قال أهل العلم: هذان الحديثان يجمعان الدين كله، حديث

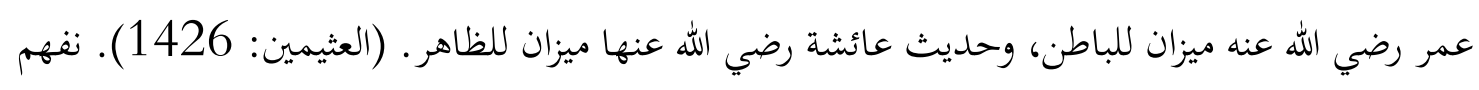

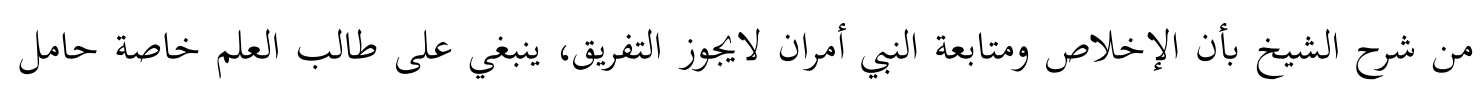

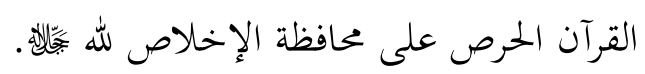

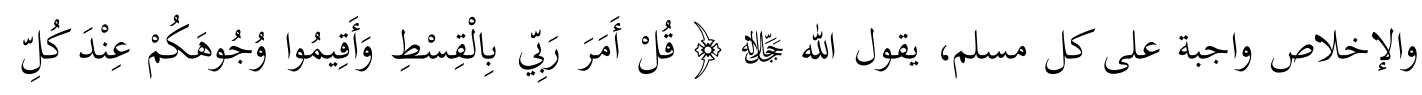

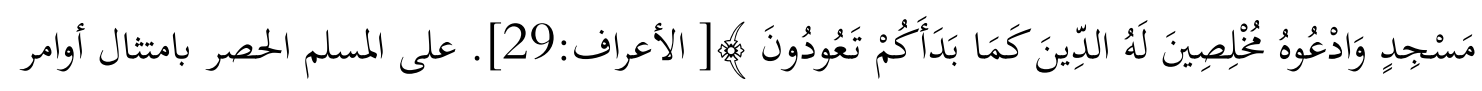
الله 2.

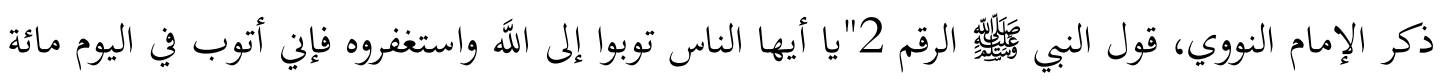

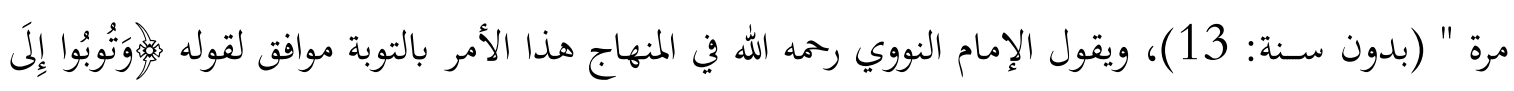

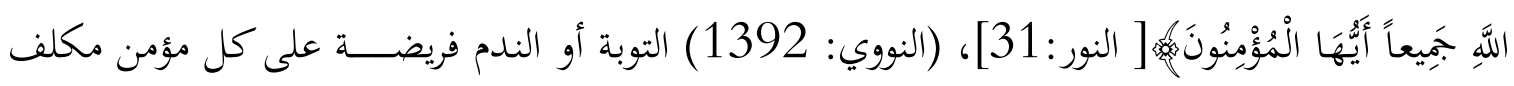

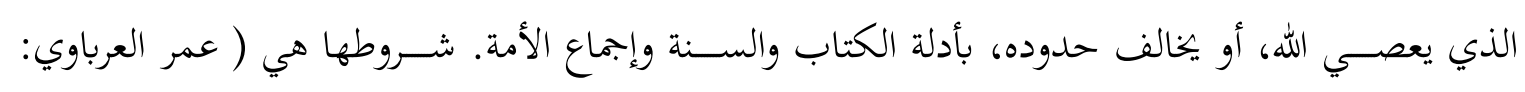

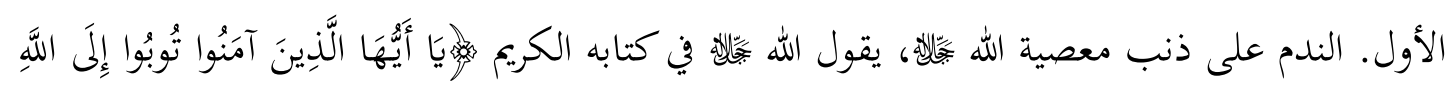

$$
\text { تَوبَبَّ نَصُوحاً }
$$

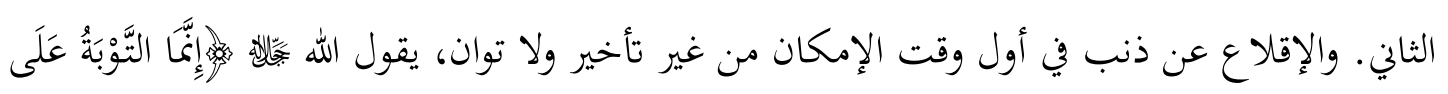

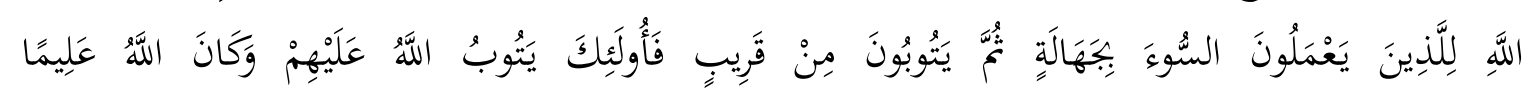

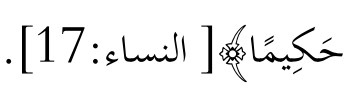

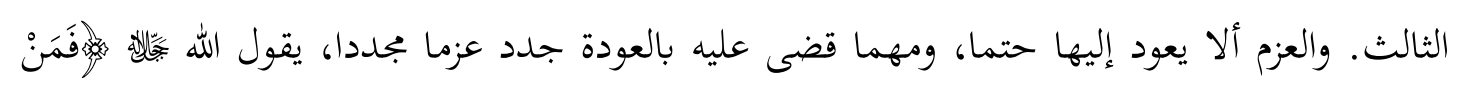

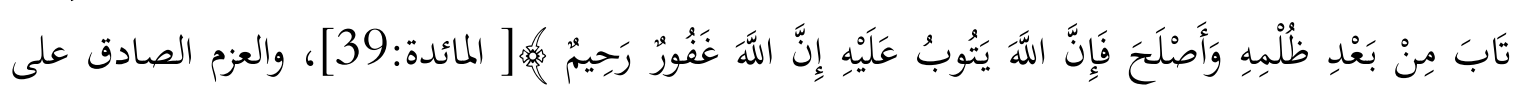
طاعة الله.

الرابع. تصفي النفس من رواسب الأثام وتلاقيها بالأعمال الصالحة. (زينة كريم عبيد: 2017) 3.

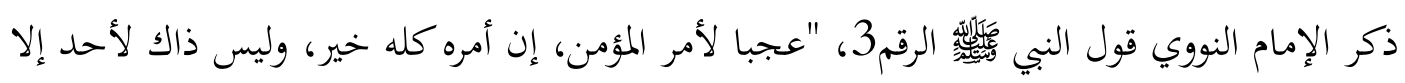

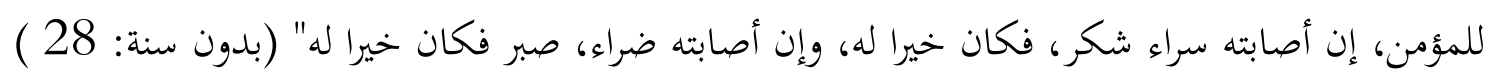

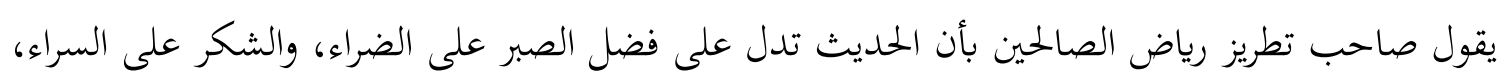

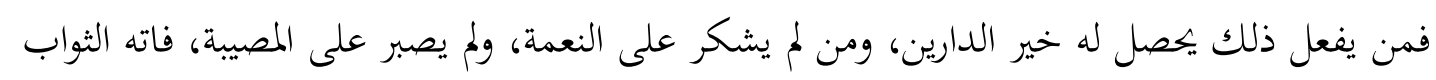

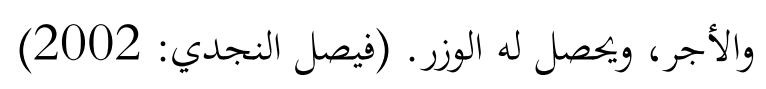

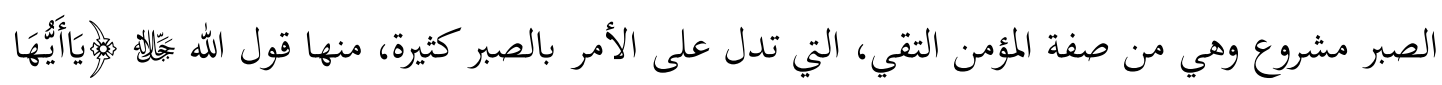

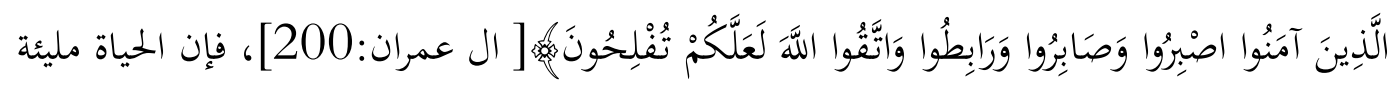


بالمصاعب والمصائب إذا صبر المسلم ابتغاء لوجه الله فسيحصل على فضائل وفيرة منها الخير في أمره كله والفلاح في الدنيا والأخرة، على طالب العلم الحرص على امتثال أوامر الله ورسوله. 4.

ذكر الإمام النووي رحمه الله الحديث الرقم 1، رواية عن أبي هريرة رضي اللَّ عنه قال : قيل : يا رسول اللَّ

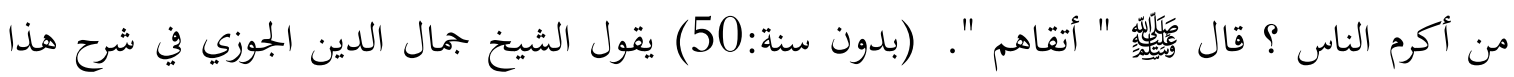

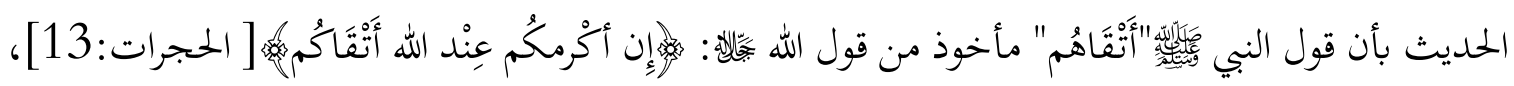

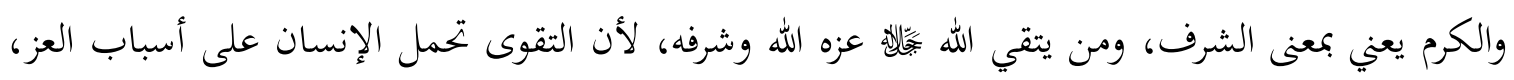

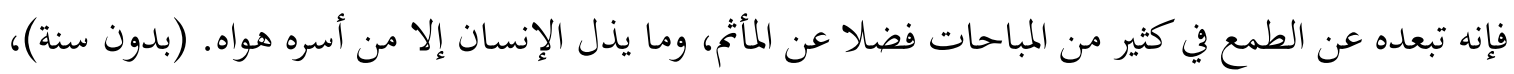
التقي سيحصل على فضائل منها

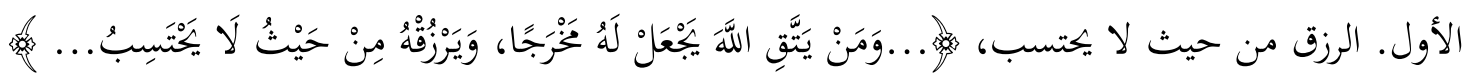

[الطلاق:2-2 [الأ.

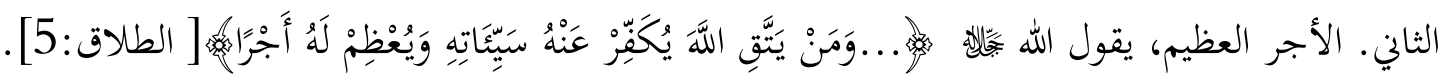

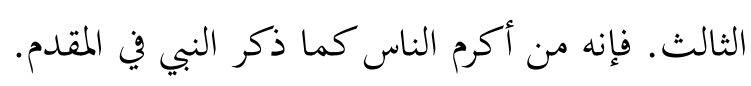

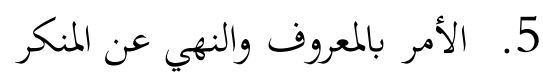

ذكر الإمام النووي رمهه الله الحديث الرقم1، في رواية عن أبي سعيد الحدري قال: سمعت رسول الله

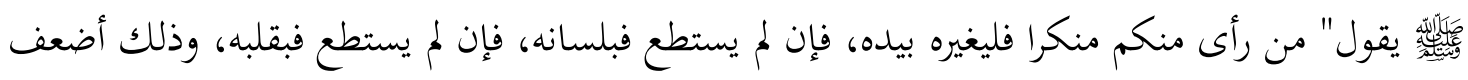

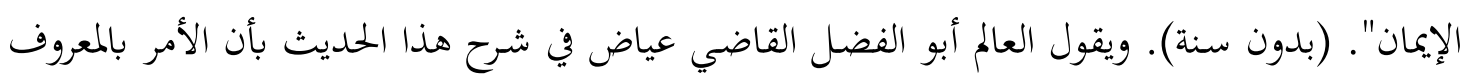

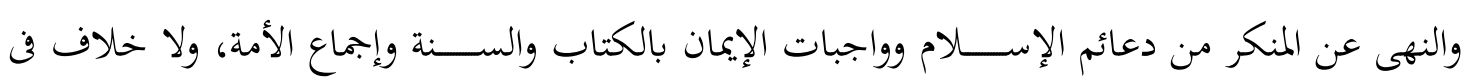

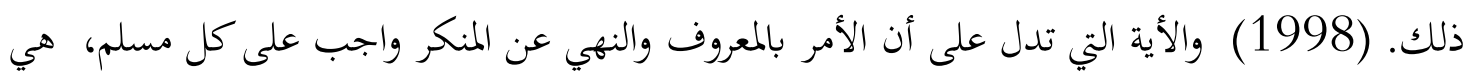

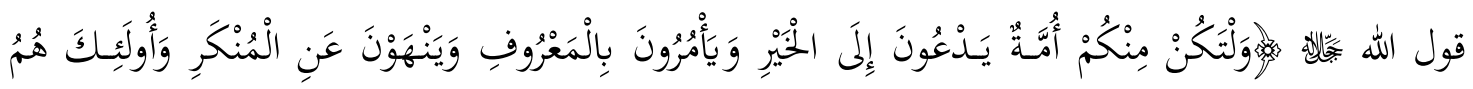

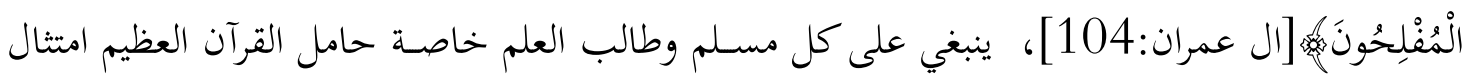

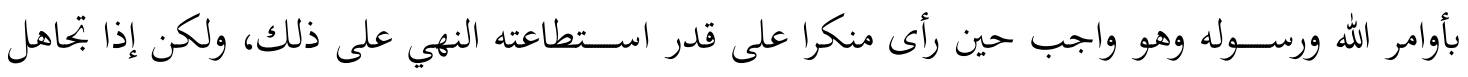

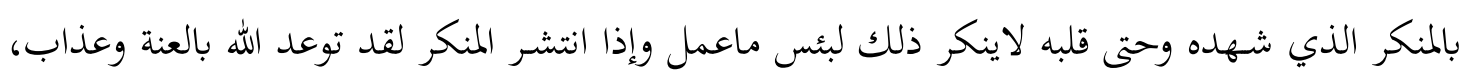

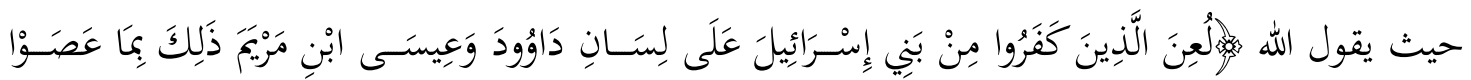

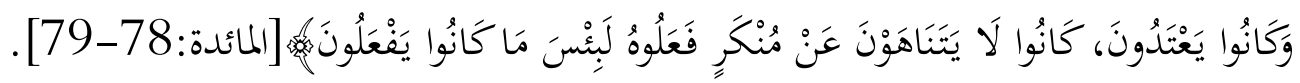

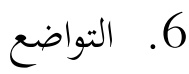

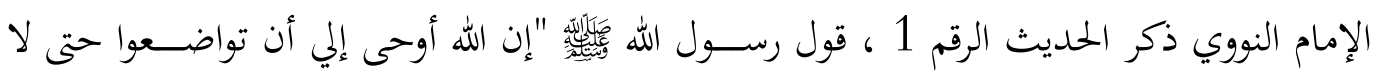

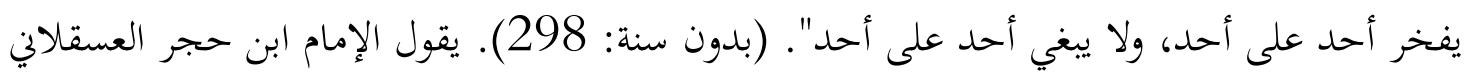

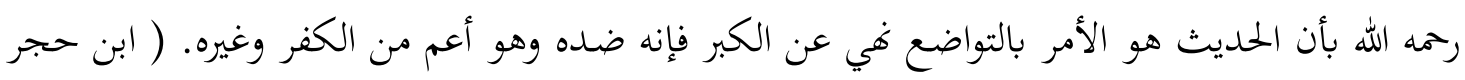

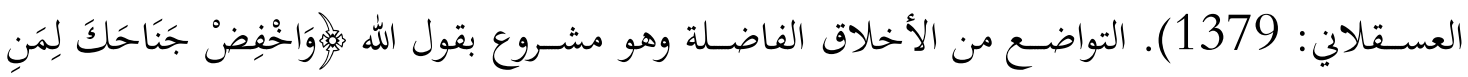




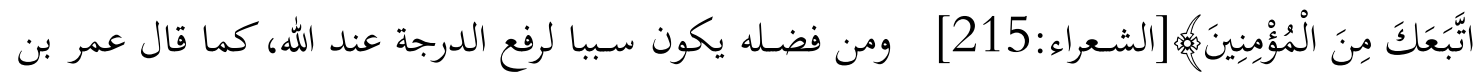

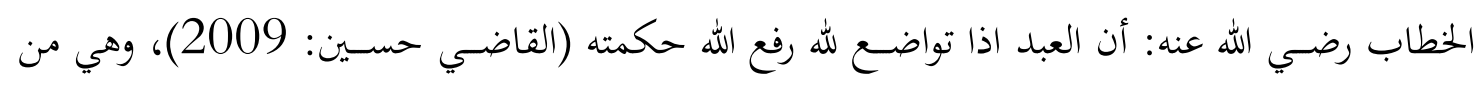

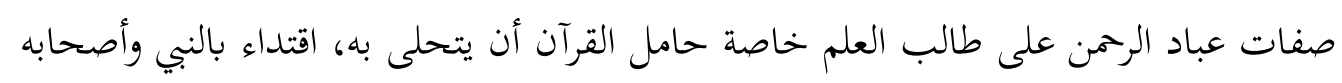

\section{الحلاصة}

بناء على الدراسة التي أجراها الباحث حول مناهج التربية الأخلاقية المستنبطة من الكتاب رياض الصالحين

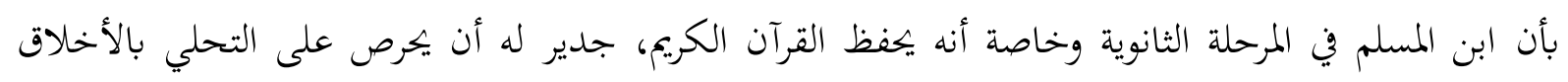

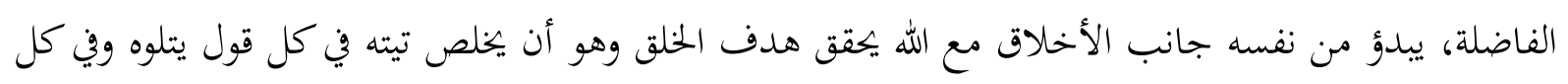

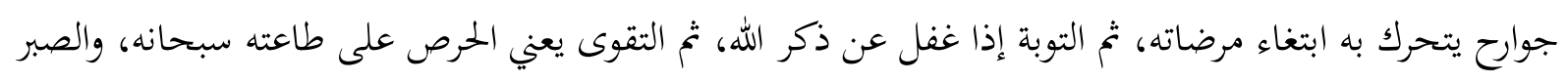

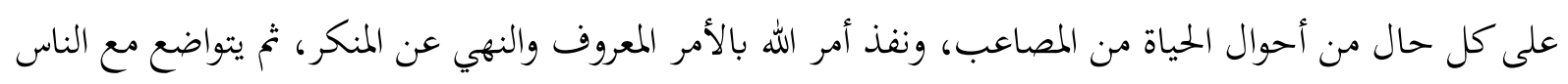
أجمعين. فإذا استقام المسلم بتلك الصفات الفاضلة فيسره الله جزاء حسنا.

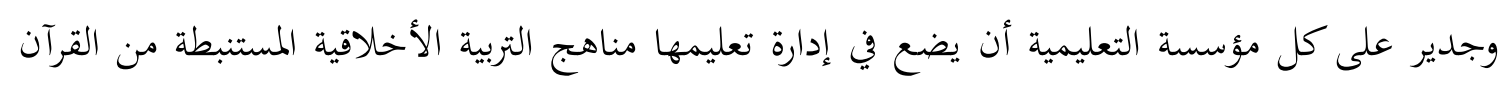

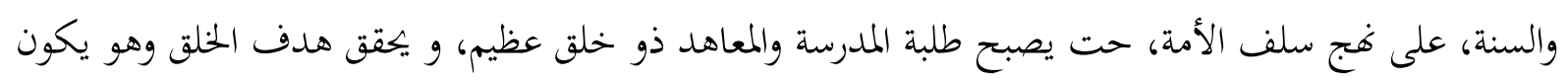
خليفة الله في الأرض. تلجن

\section{المراجع}

عبيد، زينة كريم. ( 1438هـ/ 2017م). التوبة بين القرآن الكريم وهتج البلاغة، وزارة التعليم والبحث علمي، جامعة القادسية.

العقيل، عبد الله بن عقيل. ( 1432هـ/2011م) مامعة الفادية. التربية الإسلامية، مكتبة الرشد.

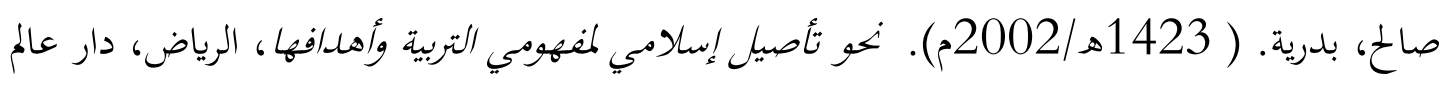
الكتب.

الخطيب، محمد شحات. ( 1421هـ/ 2000م). أصول التربية الإسلامية، الرياض، دار الخريجي للنشر

والتوزيع.

الجرجاني، علي. ( 1403هـ -1983م ). التعريفات، لبنان، دار الكتب العلمية.

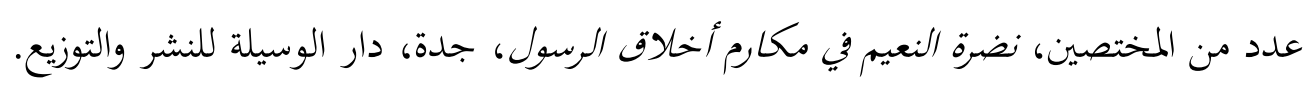
النووي، رياض الصالحين، سورابايا، دار العلم.

الألباني، ناصر الدين. (1422هـ/ 2002م). مختصر صحيح البخاري، الرياض، مكتبة المعارف.

العثيمين، محمد صالح. (1426هـ). شرح رياض الصالحين، المملكة العربية السعودية. النووي،1392هـ، المنهاج، بيروت، دار إحياء التراث العربي. 
العرباوي، عمر، 1404هـ /1984م، كتاب التوحيد، ، مطبعة الوراقة العصرية. النجدي، فيصل .( 1423هـ/2002م. تطريز رياض الصالحين. الرياض: دار العاصمة.

$$
\begin{aligned}
& \text { مسلم،صحيح مسلم. } \\
& \text { الجوزي، جمال الدين، كشف المشكل من حديث الصحيحين. الرياض: دار الوطن. }
\end{aligned}
$$

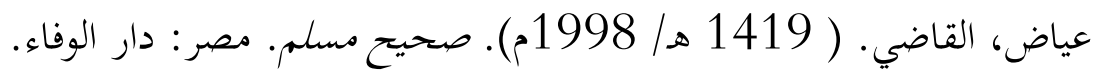

$$
\begin{aligned}
& \text { العسقلاني، ابن حجر. (1379 هـ) . فتح الباري. بيروت: دار المعرفة. }
\end{aligned}
$$

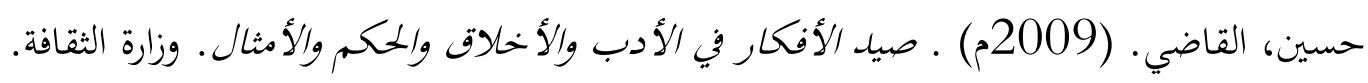
مجمع اللغة العربية. (1432هـ/2011م) ـ المعجم الوسيط. القاهرة: مكتبة الشروق الدولية. الفوزان، عبد الرحمن بن إبراهيم وغيره. (1435هـ). المعجم العربي بين يديك، المملكة العربية السعودية. Sarinah. (2012). Pengantar Kurikulum. Yogyakarta: DeePubliser.

Hamalik, Oemar. (2010). Kurikulum Dan Pembelajaran. Jakarta: Bumi Aksara. 